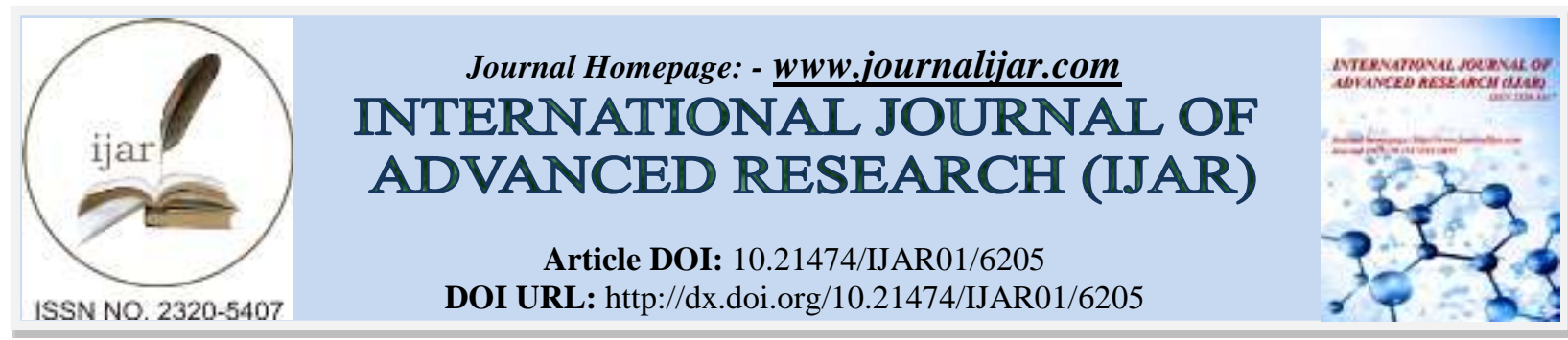

RESEARCH ARTICLE

\title{
EVALUATION OF POST-OPERATIVE PAIN AFTER IRRIGATION USING END-VENTED NAVITIP TIPS VERSUS SIDE-VENTED NAVITIP TIPS IN TEETH WITH IRREVERSIBLE PULPITIS: A RANDOMIZED CLINICAL TRIAL PART VI.
}

\section{Hamdy $\mathbf{M}^{\mathbf{1}}$, Ghoneim $\mathrm{AG}^{2}$ and Alasfori $\mathrm{H}^{3}$.}

1. Master's Degree in Endodontics, Faculty of Oral and Dental Medicine, Cairo University, Egypt.

2. Professor in Endodontics Department, Faculty of Oral and Dental Medicine, Cairo University, Egypt.

3. Lecturer in Endodontics Department, Faculty of Oral and Dental Medicine, Cairo University, Egypt.

\section{Manuscript Info}

(.........................

Manuscript History

Received: 03 November 2017

Final Accepted: 05 December 2017

Published: January 2018

Keywords:-

End-Vented needle, Irrigation, Postoperative pain, Side-Vented needle.

\section{Abstract}

Objectives: The aim of this prospective randomized clinical trial was to compare the degree of post-operative pain and analgesic intake at 0 , $4,12,24,48,72$-hrs and 7 days after the use of two different irrigation needles.

Subjects and Methods: Thirty eight participants diagnosed with symptomatic or asymptomatic irreversible pulpitis in mandibular posterior teeth received single-visit root canal treatment and were divided randomly into two groups according to the type of needle used during irrigation either NaviTip 29-gauge, $27 \mathrm{~mm}$ with End-Vented needle $(\mathrm{EVN})$ or NaviTip 31-gauge, $27 \mathrm{~mm}$ with Double Sideport Irrigator Tip (SVN). Post-operative pain was measured using Numeric Rating Scale (NRS) pre-operatively, immediate post-operatively and at 4, 12, 24, 48, 72-hrs and 7 days. Placebo and analgesic intake was recorded at the different time intervals.

Results: there was no difference between both groups in the NRS scores at all the post-operative time intervals. An observable increase in pain levels was recorded at 4-hrs followed by an observable drop in pain levels at 12, 24 and 48-hrs post-operatively until pain disappeared at 7 days with no difference in drug intake post-operatively between both groups.

Copy Right, IJAR, 2018,. All rights reserved.

\section{Introduction:-}

The goal of endodontic treatment is to remove inflamed vital and necrotic pulp remnants from the pulp space and to prevent the occurrence of periradicular diseases, or promote healing of already existing pathosis ${ }^{(1)}$. Successful endodontic treatment can be achieved through proper chemo-mechanical preparation as mechanical instrumentation only is insufficient for complete cleaning and shaping of the root canal system due to the complex anatomy harboring tissue debris and microbes ${ }^{(2)}$.

Sodium hypochlorite is the gold standard irrigant used for root canal disinfection in endodontic treatment due to its tissues dissolving ability, antibacterial effect, biofilm destruction and endotoxins inactivation ${ }^{(3)}$. The extrusion of sodium hypochlorite beyond the apex causes severe irritation to the periapical tissues causing pain, swelling and 
tissue damage ${ }^{(4)}$. Other irrigants such as hydrogen peroxide may cause pain and emphysema if it reaches the periapical tissues ${ }^{(4)}$.

Post-operative pain is a common finding after endodontic treatment, its incidence ranges from $3 \%$ to $58 \%$ in single and multiple visit treatment. It may be due to microbial, mechanical, or chemical injury to the periapical tissues ${ }^{(5)}$, such as irrigant extrusion beyond the apex.

The problem with needle irrigation is the need for close proximity of the irrigation needle to the apex to improve the irrigation efficacy. However, the closer the needle tip is positioned to the apical tissue, the greater is the chance of apical extrusion of the irrigant ${ }^{(6)}$. Sodium hypochlorite extrusion beyond the apex causes severe irritation to the periapical tissues leading to pain, swelling and tissue damage ${ }^{(4)}$.

However the use of safe-end side-vented needle close to the apex during irrigation decreases the risk of irrigant extrusion ${ }^{(7)}$, and few studies investigated the effect of irrigation devices and methods on post-operative pain ${ }^{(8,9)}$, thus the aim of this study was to compare the degree of post-operative pain after the use of side-vented and end vented needles.

\section{Subjects and Methods:-}

The trial design of this study was a prospective randomized clinical trial, the patients were asked to follow the general instructions and to sign a printed informed consent after the explanation of the treatment procedures.

\section{Patient Selection:-}

Patients were carefully diagnosed and checked for the eligibility criteria through careful medical history, dental history, extra-oral and intra-oral clinical examination, visual examination of the suspected tooth, percussion test and pulp testing, in addition to proper intra-oral radiographic assessment.

Thirty-eight participants diagnosed with symptomatic or asymptomatic irreversible pulpitis in mandibular posterior teeth were included in this study. Patients' age was in range of 18-60 yrs. Patients taking any medication that would affect pain perception, patients suffering from systemic diseases that could affect treatment, pregnant patients and patients allergic to any medication used in the study, in addition to patients with necrotic teeth, periapical radiolucency, swelling, sinus tract, grade two or three mobility or retreatment cases were all excluded from the study.

Recording of the chief complaint and history of presence or absence of pain in the patient's own words was done. If there was a history of pain, a determination of pain criteria: intensity, character, duration, frequency, provoking and relieving factors and localization was done. The patient was asked to mark the level of pain experienced preoperatively in the pain diary and the analgesic intake.

\section{Randomization:-}

Random sequence was generated by the Center of Evidence Based Dentistry, Faculty of Oral and Dental Medicine, Cairo University using the random function in Microsoft Excel software for 38 participants and each participant was assigned a letter $\mathrm{C}$ for control and $\mathrm{I}$ for intervention with 19 participants in each group. The sequence table was kept with the co-investigator. Each participant was given a number from 1-38 after he/she was confirmed eligible for the study after access cavity preparation. Based on the number the patient was then allocated into intervention or control group after contacting the co-investigator and asking him about which group the number stands for. Blinding was done for the patient, as he/she was not informed of the irrigation needle type and for the outcome assessor that collected the NRS and analgesic consumption data from the patients. The operator could not be blinded due to the nature of the study as the needles' vents must be exposed and could not be masked.

\section{Endodontic Protocol:-}

Patients were anaesthetized using the inferior alveolar nerve block technique using $2 \% \mathrm{Mepivacaine} \mathrm{HCl}$ with 1:20,000 Levonordefrin (MEPECAINE-L ALEX CO. for Pharmaceuticals and Chemical Industries, Egypt.). Intrapulpal anesthesia was given if there was still pain then the tooth was disinfected using chlorhexidine mouthwash.

Access cavity was prepared, teeth isolated using rubber dam, and working length was determined using electronic apex locator, which was confirmed radiographically at $0.5-1 \mathrm{~mm}$ shorter than the radiographic apex. Root canals 
were instrumented using ProTaper Universal nickel-titanium rotary instruments (ProTaper Universal Dentsply, Tulsa dental, Densply Maillefer, USA) in a crown down technique using 19\% EDTA cream as lubricant with each file.

The patients were randomly divided into two equal groups according to the needle type used during irrigation; Group A, NaviTip® 29-gauge 27-mm (Ultradent Products Inc., South Jordan, UT, USA) with End-Vented Tip (EVN) and Group B, NaviTip® 31-gauge 27-mm (Ultradent Products Inc., South Jordan, UT, USA) with Double Sideport Irrigator Tip (SVN). Irrigation was done using freshly prepared $2.5 \% \mathrm{NaOCl}$ to maintain chlorine stability and performed $2 \mathrm{~mm}$ short of the final working length. Eight milliliters of $2.5 \% \mathrm{NaOCl}$ were used during access cavity preparation and initial coronal instrumentation then $2 \mathrm{ml}$ of $2.5 \% \mathrm{NaOCl}$ was expressed over 30 seconds after each rotary instrument use and $3 \mathrm{ml}$ of $17 \%$ EDTA was used for 1 minute followed by $10 \mathrm{ml}$ of distilled water as a final flush.

After completion of instrumentation and irrigation, Obturation was done using Protaper Universal gutta-percha cones (ProTaper Universal Gutta Percha Dentsply, Tulsa dental, Densply Maillefer, USA.) corresponding to the final finishing file and Resin based sealer (ADSEAL META BIOMED CO., LTD., Korea.), using the modified single cone technique. A radiograph was obtained to ensure proper master cone extension. Obturation was considered complete when the spreader can no longer penetrate beyond the cervical line. Excess gutta-percha was cut off using a heated plugger and teeth were then sealed using Cavit. All procedures were done in a single-visit and all steps were checked radiographically.

\section{Post-operative pain evaluation:-}

After the treatment, all patients received post-operative instructions and an emergency kit containing one capsule of placebo packed with starch and a prescription for $200 \mathrm{mg}$ ibuprofen. Patients were instructed to take the placebo within the 0-4-hrs time interval after the treatment if needed. If the pain was not relieved, the patients were instructed to call the doctor for consultation and the doctor would allow the use of the prescription as one or more tablets of analgesic every 8-hrs.

Post-operative pain was measured at immediate post-operatively, 4, 12, 24, 48 and 72-hrs and 7 days after root canal treatment in addition to a pre-operative record using Numeric Rating Scale (NRS) scale, which is a 10-cm line with 11 marks and 10 intervals. Pain was categorized into four categorical scores: none, mild [1-3], moderate [4-6], severe [7-10]. Secondary outcomes measured were the placebo intake incidence, analgesic intake incidence and number of analgesic pills needed at each time point as recorded by the patient.

\section{Results:-}

The side-vented and end-vented needles showed an observable drop in pain levels at all the time points compared to the pre-operative pain levels until pain disappeared. The results also showed an observable increase in pain levels at 4-hrs in both groups compared to the immediate post-operative pain levels. (Table 1 and Figure 1)

The end-vented needle showed higher pain levels at 4-hrs and lower pain levels at 12-hrs and 24-hrs compared with the side-vented needle. However, there was no statistically significant difference $(p>0.05)$ in the pain levels between both groups at all the post-operative time points.

There was no statistically significant difference $(\mathrm{p}>0.05)$ between the two tested groups regarding placebo intake incidence, medication intake incidence, or Ibuprofen pills intake. (Figure 2)

Table 1:- Median, minimum and maximum NRS scores at different time points in both groups; (Group A: EVN and Group B: SVN) by Mann Whitney test and over time in each group by Friedman Test.

\begin{tabular}{|l|c|c|c|c|c|c|c|}
\hline & \multicolumn{3}{|c|}{ Group A } & \multicolumn{3}{c|}{ Group B } & Min. \\
\hline & Median & Min. & Max. & Median & $p$-value 1 \\
\hline Pre-operative & 7 & 5 & 10 & 7 & 0 & 9 & 0.721 \\
\hline Immediate & 0 & 0 & 9 & 0 & 0 & 9 & 0.319 \\
\hline 4 Hours & 7 & 0 & 10 & 6 & 1 & 10 & 0.930 \\
\hline 12 Hours & 4 & 0 & 10 & 5 & 0 & 10 & 0.397 \\
\hline
\end{tabular}




\begin{tabular}{|l|l|l|l|l|l|l|l|}
\hline 24 Hours & 3 & 0 & 6 & 4 & 0 & 7 & 0.700 \\
\hline 48 Hours & 0 & 0 & 6 & 0 & 0 & 4 & 0.972 \\
\hline 72 Hours & 0 & 0 & 4 & 0 & 0 & 5 & 0.080 \\
\hline 7 Days & 0 & 0 & 0 & 0 & 0 & 2 & 0.418 \\
\hline$p$-value 2 & \multicolumn{7}{|c|}{$0.001^{*}$} \\
\hline
\end{tabular}

Indicates significance at $\mathrm{p} \leq 0.05$

p-value 1 for comparison between both groups.

p-value 2 for comparison over time in each group separately.

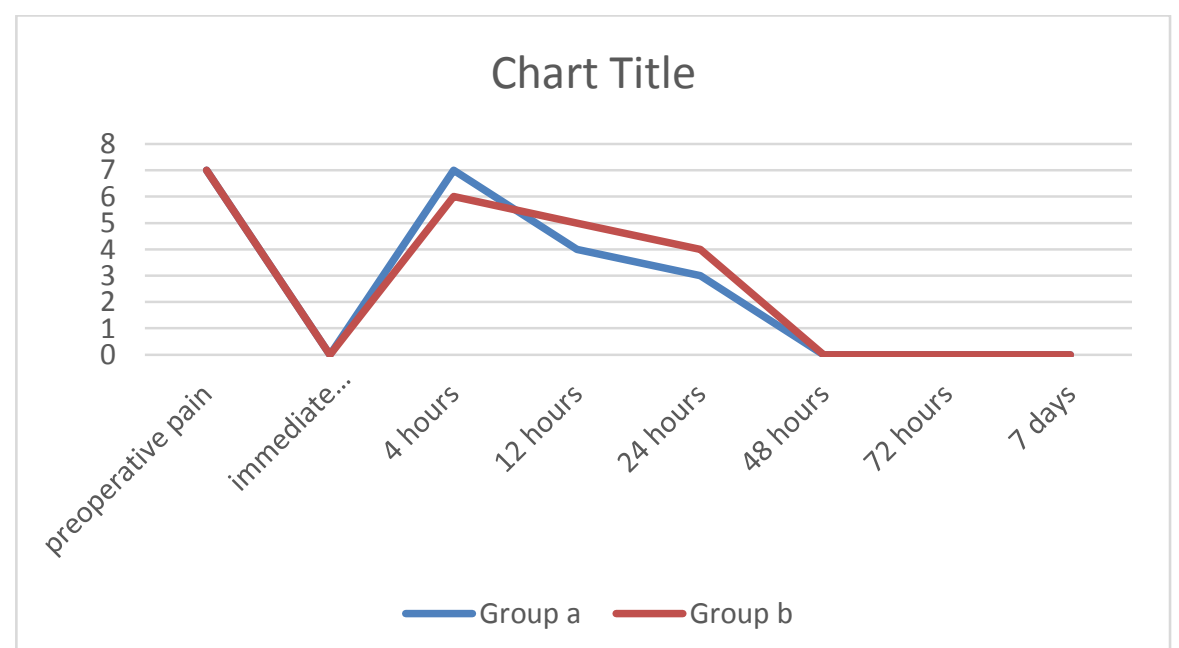

Figure 1:- Line chart showing the change in the NRS scores values over time for the two groups; (Group A: EVN and Group B: SVN).

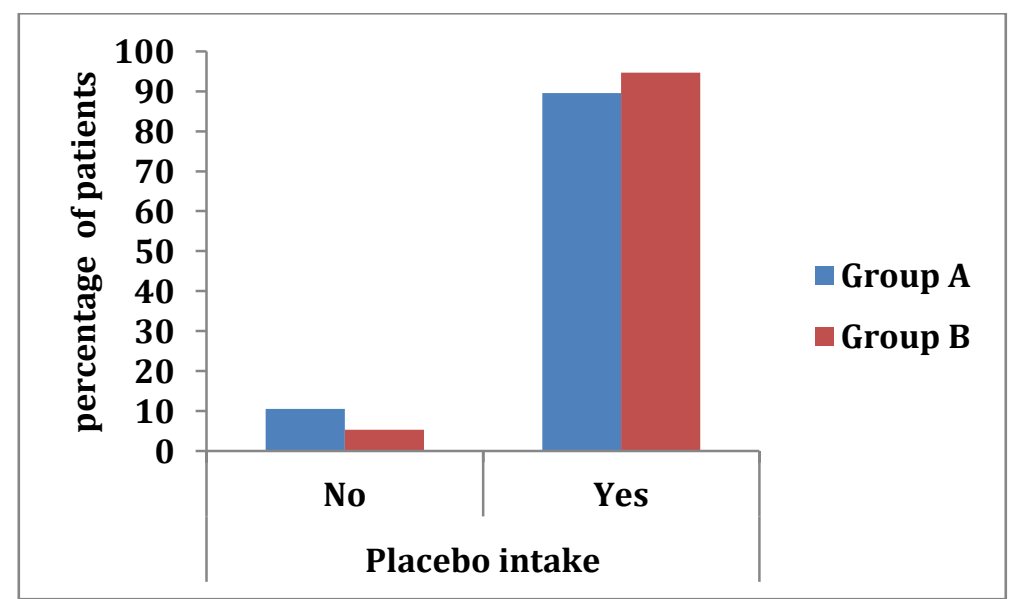

Figure 2:- Bar chart representing Placebo intake distribution in the two tested groups; (Group A: EVN and Group B: SVN). 


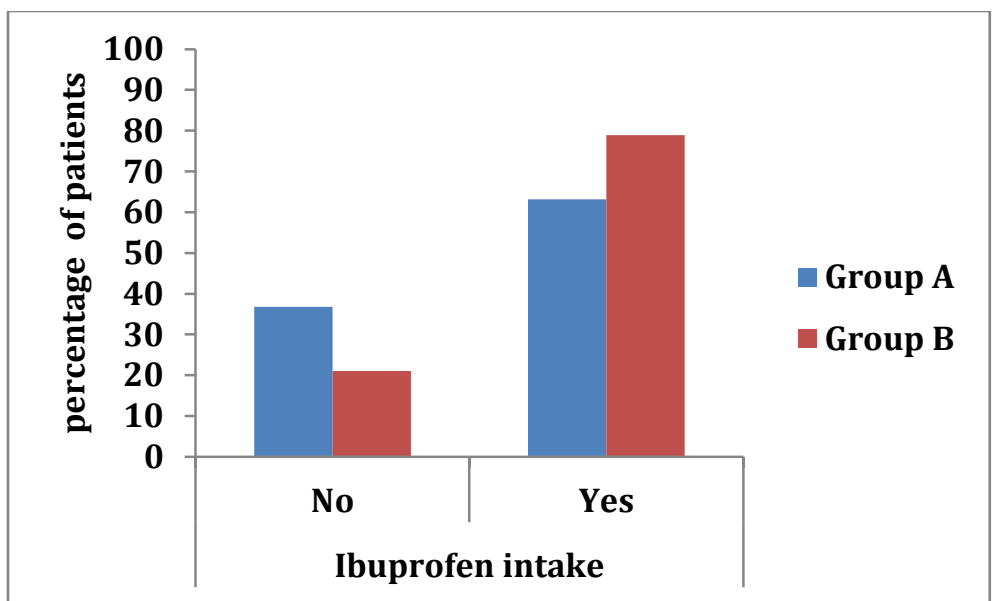

Figure 3:- Bar chart representing Ibuprofen intake distribution in the two tested groups; (Group A: EVN and Group B: SVN).

\section{Discussion:-}

Development of post-operative pain after root canal treatment is a common finding. Several risk factors such as gender and age, number of visits, type of intracanal medication used, presence of pre-operative pain, pulpal and periradicular diagnosis and apical extrusion of debris have been correlated with the occurrence of flare-ups ${ }^{(10)}$.

Teeth with irreversible pulpitis were selected in this study to reduce the risk of exacerbation by residual microorganisms found in teeth with necrotic pulp, teeth with apical periodontitis or re-treatment cases ${ }^{(10)}$. Moreover, mandibular posterior teeth were selected due to higher incidence of pain in comparison with maxillary anterior teeth because of the mandibular dense trabecular pattern, that reduces the blood flow and causes localization of infection and exudates leading to delayed healing patterns ${ }^{(11)}$.

Root canal treatment was completed in a single-visit as Wong et al. (2015) ${ }^{(12)}$ reported that there was no statistically significant difference in post-obturation pain incidence after one day and seven days between single-visit or multivisit endodontic treatments. In addition, single-visit treatment has more advantages such as reducing the risk of flare-up induced by leakage of the temporary seal between appointments, moreover it reduces patient's appointments per tooth, allows for immediate use of canal for retention of posts, helps to avoid multiple injections and rubber dam placement and reduces procedural costs ${ }^{(13)}$.

Root canal preparation was performed by crown-down technique using ProTaper Universal rotary system, this was in agreement with Nekoofar et al. (2015) ${ }^{(14)}$ who concluded that post-operative pain was significantly lower with ProTaper Universal rotary instruments compared with WaveOne reciprocating instruments and Arias et al. (2015) ${ }^{(15)}$ who found that more post-operative pain occurred after step-back manual instrumentation than after crown-down rotary instrumentation.

In this study, $2.6 \% \mathrm{NaOCl}$ was used as routine irrigant due to its broad antibacterial activity and organic material dissolution ability ${ }^{(16)}$. A low concentration of $2.6 \% \mathrm{NaOCl}$ was used due to less toxicity and same antibacterial efficacy compared with higher concentration of $5.25 \% \mathrm{NaOCl}^{(17,18)}$.

Three milliliters of $17 \%$ EDTA was used for smear layer removal as $\mathrm{NaOCl}$ lacks the ability to dissolve inorganic material ${ }^{(19)}$ and $10 \mathrm{ml}$ of distilled water were used immediately after EDTA to avoid the prolonged effect of the chelating agent on the micro-hardness of root dentin and adhesion to resin-based sealers ${ }^{(20)}$.

The needles were placed $2 \mathrm{~mm}$ short from working length during irrigation as Boutsioukis et al. (2010) ${ }^{(6)}$ suggested that 2-3 $\mathrm{mm}$ short of working length would ensure adequate irrigant exchange without causing high apical pressure. 
Modified single cone technique was used for obturation in this study according to Alonso-Ezpeleta et al. (2012) (21) who found that the incidence and intensity of pain after cold lateral condensation was lower than vertically condensed Thermafil and Peng et al. (2007) ${ }^{(22)}$ who found that warm gutta percha obturation caused a higher rate of over-extension than cold lateral condensation after a meta-analysis of 10 clinical studies.

The Numeric Rating System (NRS) was used to evaluate the pain intensity as it provides a descriptive numerical value to the patient and for statistical analysis. It is preferred by patients and clinicians over the Visual Analogue Scale (VAS) for its relative simplicity, ease of administration and scoring ${ }^{(23)}$.

Assessment of post-operative pain was done immediately post-operative and after 4, 12, 24, 48 and 72 -hrs and 7 days ${ }^{(8,9)}$ to record any difference in pain intensity between both groups as Tang et al. (2015) ${ }^{(24)}$ reported higher pain intensity with needle irrigation compared to ultrasonic irrigation even after 7 days. Pre-operative pain was measured as Ali et al. (2016) ${ }^{(25)}$ showed that the presence of pre-operative pain is the most influencing variable on post-operative pain prevalence.

The side-vented and end-vented needles showed an observable drop in pain levels until pain disappeared, this was in accordance to Pak et al. (2011) ${ }^{(26)}$ who reported that post-treatment pain decreased substantially after 1-2 days of treatment and continued to drop to minimal levels after 7 days. The results of this study showed an observable increase in pain levels at 4-hrs in both groups compared to the immediate post-operative pain levels, this may be related to the loss of local anesthetic effect ${ }^{(27)}$. This was in agreement with the results of Gondim et al. (2010) ${ }^{(8)}$ and Al-Zaka (2012) ${ }^{(9)}$ that showed that the highest levels of pain occurred at 0-4-hrs and then decreased at 24 and 48-hrs.

The end-vented needle showed higher pain levels at 4-hrs and lower pain levels at 12-hrs and 24-hrs compared with the side-vented needle. However, there was no statistically significant difference in the pain levels between both groups at all the post-operative time points, this was in agreement with Uzunoglu et al. (2015) ${ }^{(28)}$ who reported no difference in the apical extrusion but in contrast to Altundasar et al. (2011) ${ }^{(7)}$ who reported higher apical extrusion by the end-vented needle than the side-vented needle.

Psychological factors such as pain anticipation may affect the patients' perception and reporting of post-operative pain incidence and intensity ${ }^{(29)}$, therefore a single placebo capsule filled with starch was given to the patients if they felt pain after the treatment before allowing analgesic intake to avoid masking the pain. The results of the study showed no difference in placebo intake between both groups.

Ibuprofen was prescribed in case of continued pain after the intake of the placebo capsule as it is the standard medication for post-operative pain relief after root canal treatment ${ }^{(30)}$ and was proven to provide similar pain relief compared to other analgesics ${ }^{(31,32)}$. A low dose of $200 \mathrm{mg}$ allows for a better measure of pain intensity and analgesic intake, as higher doses may obscure the outcome ${ }^{(33)}$. The results of the study showed no difference in ibuprofen intake between the two groups at all the time points.

\section{Conclusion:-}

Within the limitations of this study, it could be concluded that the Side-Vented and End-Vented NaviTip needles caused more or less similar post-operative pain in patients with irreversible pulpitis in mandibular posterior teeth after single-visit endodontic treatment and it could be recommended to use the Side-Vented or End-Vented NaviTip needles for irrigation with the described irrigation protocol. 


\section{References:-}

1. European Society of Endodontology. Quality guidelines for endodontic treatment: consensus report of the European Society of Endodontology. Int Endod J 2006; 39: 921-930.

2. Burleson A, Nusstein J, Reader A, Beck M. The In Vivo Evaluation of Hand/Rotary/Ultrasound Instrumentation in Necrotic, Human Mandibular Molars. J Endod 2007; 33: 782-787.

3. Mohammadi Z. Sodium hypochlorite in endodontics: an update review. Int Dent J 2008; 58: 329-341.

4. Hulsmann M. Complications during root canal-irrigation-literature, review and case reports. Int Endod J 2000; 33: 186-193.

5. Sathorn $\boldsymbol{C}$, Parashos $\boldsymbol{P}$, Messer $\boldsymbol{H}$. The prevalence of postoperative pain and flare-up in single- and multiplevisit endodontic treatment: a systematic review. Int Endod J 2008; 41: 91-99.

6. Boutsioukis C, Lambrianidis T, Verhaagen B, Versluis M, Kastrinakis E, Wesselink PR, et al. The effect of needle-insertion depth on the irrigant flow in the root canal: evaluation using an unsteady computational fluid dynamics model. J Endod 2010; 36: 1664-1668.

7. Altundasar E, Nagas E, Uyanik $\boldsymbol{O}$, Serper A. Debris and irrigant extrusion potential of 2 rotary systems and irrigation needles. Oral Surg Oral Med Oral Pathol Oral Radiol Endod 2011; 112: e31-35.

8. Gondim E, Setzer FC, Dos Carmo CB, Kim S. Postoperative pain after the application of two different irrigation devices in a prospective randomized clinical trial. $J$ Endod 2010; 36: 1295-1301.

9. Al-Zaka IM. The incidence of pain after root canal treatment using different irrigation methods. Tikrit J Dent Sci 2012; 1: 38-43.

10. Onay EO, Ungor M, Yazici AC. The evaluation of endodontic flare-ups and their relationship to various risk factors. BMC Oral Health 2015; 15: 142.

11. Ali SG, Mulay S, Palekar A, Sejpal D, Joshi A, Gufran H. Prevalence of and factors affecting post-obturation pain following single visit root canal treatment in Indian population: A prospective, randomized clinical trial. Contemp Clin Dent 2012; 3: 459-463.

12. Wong AW-Y, Zhang S, Li SK-Y, Zhu X, Zhang C, Chu $\boldsymbol{C}-\boldsymbol{H}$. Incidence of post-obturation pain after singlevisit versus multiple-visit non-surgical endodontic treatments. BMC Oral Health 2015; 15: 96.

13. Figini L, Lodi G, Gorni F, Gagliani M. Single versus multiple visits for endodontic treatment of permanent teeth: a Cochrane systematic review. J Endod 2008; 34: 1041-1047.

14. Nekoofar MH, Sheykhrezae MS, Meraji N, Jamee A, Shirvani A, Jamee J, et al. Comparison of the effect of root canal preparation by using WaveOne and ProTaper on postoperative pain: a randomized clinical trial. $J$ Endod 2015; 41: 575-578.

15. Arias A, de la Macorra JC, Azabal M, Hidalgo JJ, Peters OA. Prospective case controlled clinical study of post-endodontic pain after rotary root canal preparation performed by a single operator. J Dent 2015; 43: 389395.

16. Gonçalves LS, Rodrigues RCV, Andrade Junior CV, Soares RG, Vettore MV. The effect of sodium hypochlorite and chlorhexidine as irrigant solutions for root canal disinfection: A systematic review of clinical trials. J Endod 2016; 42: 527-532.

17. Ghisi AC, Kopper PMP, Baldasso FER, Stürmer CP, Rossi-Fedele G, Steier L, et al. Effect of superoxidized water and sodium hypochlorite, associated or not with EDTA, on organic and inorganic components of bovine root dentin. J Endod 2015; 41: 925-930.

18. Siqueira JF, Rôças IN, Favieri A, Lima KC. Chemomechanical reduction of the bacterial population in the root canal after instrumentation and irrigation with $1 \%, 2.5 \%$, and 5.25\% sodium hypochlorite. J Endod 2000; 26: 331-334.

19. Haapasalo M, Shen Y, Qian W, Gao Y. Irrigation in Endodontics. Dent Clin North Am 2010; 54: $291-312$.

20. Sayin TC, Serper A, Cehreli ZC, Otlu HG. The effect of EDTA, EGTA, EDTAC, and tetracycline-HCl with and without subsequent $\mathrm{NaOCl}$ treatment on the microhardness of root canal dentin. Oral Surg Oral Med Oral Pathol Oral Radiol Endod 2007; 104: 418-424.

21. Alonso-Ezpeleta L-O, Gasco-Garcia C, Castellanos-Cosano L, Martín-González J, López-Frías F-J, SeguraEgea $\boldsymbol{J}$-J. Postoperative pain after one-visit root-canal treatment on teeth with vital pulps: comparison of three different obturation techniques. Med oral, Patol oral y cirugía bucal 2012; 17: e721-727.

22. Peng L, Ye L, Tan H, Zhou X. Outcome of root canal obturation by warm gutta-percha versus cold lateral condensation: a meta-analysis. J Endod 2007; 33: 106-109.

23. Ferreira-Valente MA, Pais-Ribeiro JL, Jensen MP. Validity of four pain intensity rating scales. Pain 2011; 152: 2399-2404.

24. Tang Z, Wang $\boldsymbol{H}$, Jiang $\boldsymbol{S}$. Clinical study of single-visit root canal treatment with a nickel-titanium (Ni-Ti) rotary instrument combined with different ultrasonic irrigation solutions for elderly patients with chronic apical 
periodontitis. Biomed Mater Eng 2015; 26 Suppl 1: S311-8.

25. Alí A, Olivieri JG, Duran-Sindreu F, Abella F, Roig M, García-Font M. Influence of preoperative pain intensity on postoperative pain after root canal treatment: A prospective clinical study. J Dent 2016; 45: 39-42.

26. Pak JG, White $S N$. Pain prevalence and severity before, during, and after root canal treatment: A systematic review. J Endod 2011; 37: 429-438.

27. Fernandez C, Reader A, Beck M, Nusstein J. A prospective, randomized, double-blind comparison of bupivacaine and lidocaine for inferior alveolar nerve blocks. J Endod 2005; 31: 499-503.

28. Uzunoglu E, Turker SA, Görduysus M. Effects of Different Rotary Files Combined with Different Irrigation Needles on Apically Extruded Debris. Braz Dent J 2015; 26: 347-350.

29. Maggirias J, Locker D. Psychological factors and perceptions of pain associated with dental treatment. Community Dent Oral Epidemiol 2002; 30: 151-159.

30. Parirokh M, Sadr S, Nakhaee N, Abbott P V., Manochehrifar H. Comparison between prescription of regular or on-demand ibuprofen on postoperative pain after single-visit root canal treatment of teeth with irreversible pulpitis. J Endod 2014; 40: 151-154.

31. Arslan H, Topcuoglu HS, Aladag $\boldsymbol{H}$. Effectiveness of tenoxicam and ibuprofen for pain prevention following endodontic therapy in comparison to placebo: a randomized double-blind clinical trial. J Oral Sci 2011; 53: 157-161.

32. Gopikrishna V, Parameswaran A. Effectiveness of prophylactic use of rofecoxib in comparison with ibuprofen on postendodontic pain. $J$ Endod 2003; 29: 62-64.

33. Ramamoorthi S, Nivedhitha MS, Divyanand MJ. Comparative evaluation of postoperative pain after using endodontic needle and EndoActivator during root canal irrigation: A randomised controlled trial. Aust Endod $J$ 2015; 41: 78-87. 